\section{Palliative sedation}

We wish to correct the inaccuracies in the CMAJ article by Tibbetts ${ }^{1}$ on Quebec's end-of-life bill. Tibbetts writes ... "hospitals in Quebec and the rest of Canada often offer palliative sedation to ease suffering. In extreme cases, doctors use 'terminal sedation,' in which patients are medicated into unconsciousness and deprived of artificial nutrition to expedite imminent death." Where the author obtained this information is unclear, but the two paragraphs that follow contain quotes from a health law ethics professor and a retired palliative care physician both of whom claim there are no "rules" and imply that this process is happening frequently.

The Canadian Society of Palliative Care Physicians formed a task force to review and develop a framework for the use of palliative sedation. ${ }^{2}$ This framework outlines the indications, decisionmaking, drugs and monitoring to be used in palliative sedation.

Tibbett's ${ }^{1}$ assertation also implies that palliative sedation hastens death by dehydrating patients who are too sedated to eat or drink. In a recent systematic review of 11 retrospective and prospective studies involving 1807 patients, with 621 patients receiving sedation, no substantial difference between sedated and nonsedated patients was found. ${ }^{3}$ A recent prospective study found that palliative sedation was a definable clinical intervention that had no effect on survival. ${ }^{4}$ Both studies noted the most frequent reason for palliative sedation was delirium.

The debate about physician-assisted death is too important of an issue to be hampered by inaccuracies and misrepresentation.

\footnotetext{
Romayne Gallagher MD, Caroline Baldwin MD

Physician Program Director, Palliative Care Program (Gallagher); palliative care physician (Baldwin) Providence Health Care; clinical instructor (Baldwin), Department of Family and Community Medicine, University of British Columbia, Vancouver, BC
}

\section{References}

1. Tibbetts J. Quebec's end-of-life bill makes palliative care more transparent. CMAJ 2013;185:1031-2.

2. Dean MM, Cellarius V, Blair H, et al. Framework for continuous palliative sedation in Canada. J Palliat Med 2012;15:870-9.

3. Maltoni M, Scarpi E, Rosati M, et al. Palliative sedation in end-of-life care and survival: a systematic review. J Clin Oncol 2012;30:1378-83.

4. Maltoni M, Miccinesi G, Morino P, et al. Prospective observational Italian study on palliative sedation in two hospice settings: differences in casemixes and clinical care. Support Care Cancer 2012;20:2829-36.

\section{CMAJ 2014. DOI:10.1503/cmaj.114-0010}

I am disappointed in Tibbett's ${ }^{1}$ reporting in $C M A J$ on terminal sedation, Bill 52 and the euthanasia debate. The following statement appears in the article: "As it stands, hospitals in Quebec and the rest of Canada often offer palliative sedation to ease suffering. In extreme cases, doctors use 'terminal sedation,' in which patients are medicated into unconsciousness and deprived of artificial nutrition to expedite imminent death."'

The term "terminal sedation" has fallen out of favour because it misrepresents the intent of the intervention. Palliative sedation, although not commonly used, is a medically respected and recognized intervention for patients with intractable symptoms, where the only option is to provide sedation to relieve suffering. Palliative sedation is normally offered only once a palliative care team has deemed symptoms to be intractable (e.g., meaning all reasonable and available avenues to relieve the patient's suffering have been tried, explored and offered), and just not difficult to manage.

Palliative sedation can be light or deep, and the intent is to relieve the patient of intractable suffering, not to end the patient's life. Patients are not "deprived" of artificial nutrition to expedite imminent death. If artificial nutrition is not a part of the care plan for the patient, it is not forced. In almost every case of palliative sedation, the patient is often near death, and to offer artificial nutrition is often futile and potentially harmful because it could cause additional symptoms.

While providing palliative care to patients, physicians often have to overcome myths and "untruths" (i.e., morphine hastens death, methadone is for patients with addictions, and patients are forced into palliative care to save the health care system money).

\section{Darren Cargill MD}

Chair, Palliative Medicine, Ontario

Medical Association, Toronto, Ont.

\section{Reference}

1. Tibbetts J. Quebec's end-of-life bill makes palliative care more transparent. CMAJ 2013;185:1031-2.

CMAJ 2014. DOI:10.1503/cmaj.114-0011

\section{Clopidogrel and proton pump inhibitors}

In their comprehensive review of antithrombotic agents following acute coronary syndromes, Matteau and Bhatt ${ }^{1}$ discuss the drug interaction between proton pump inhibitors and clopidogrel. They note that the COGENT trial, led by Bhatt, found no increased risk of major cardiovascular events at six months in patients receiving omeprazole with clopidogrel. ${ }^{2}$

The COGENT trial employed a proprietary product containing omeprazole and clopidogrel (CGT-2168) purposefully formulated to circumvent any drug interaction by releasing the two drugs separately. ${ }^{3,4}$ It offers no information about the safety of omeprazole and clopidogrel in patients who take clinically available products together.

A large and growing body of evidence suggests that omeprazole and pantoprazole exert differential effects on the antiplatelet effect of clopidogrel. ${ }^{5,6}$ Although the clinical significance of the interaction remains the subject of debate, there is no compelling reason to use omeprazole rather than pantoprazole in this setting.

\section{David Juurlink MD PhD}

Division Head, Clinical Pharmacology \&

Toxicology, University of Toronto,

Toronto, Ont.

\section{References}

1. Matteau A, Bhatt DL. Recent advances in antithrombotic therapy after acute coronary syndrome. CMAJ 2013; Nov. 4 [Epub ahead of print].

2. Bhatt DL, Cryer BL, Contant CF, et al. Clopidogre with or without omeprazole in coronary artery disease. N Engl J Med 2010;363:1909-17. 
3. Goldsmith M, Vadas B. Oral dosage forms includ ing an antiplatelet agent and an enterically coated acid inhibitor. Cogentus Pharmaceuticals: United States patent application no. 20070243243 (issued 2007 Oct. 18).

4. Juurlink DN. Clopidogrel with or without omeprazole in coronary disease. $N$ Engl J Med 2011;364:681-2.

5. Chen $\mathrm{CH}$, Yang JC, Uang YS, et al. Differential inhibitory effects of proton pump inhibitors on the metabolism and antiplatelet activities of clopidogrel and prasugrel. Biopharm Drug Dispos 2012; 33:278-83.

6. Arbel Y, et al. Platelet inhibitory effect of clopidogrel in patients treated with omeprazole, pantoprazole, and famotidine: a prospective, randomized, crossover study. Clin Cardiol 2013;36:342-6.

CMAJ 2014. DOI:10.1503/cmaj.114-0014

\section{The author responds}

The points raised by Juurlink ${ }^{1}$ in response to our article ${ }^{2}$ are worthy of consideration. The release kinetics of the drugs as given in the COGENT trial may have attenuated the potential for a drug-drug interaction. However, in the absence of any further randomized clinical trial of concomitant omeprazole and clopidogrel, extrapolation from the COGENT dataset may be the best evaluation we have of whether there is a real interaction. The observational data are mixed and cannot provide the same level of evidence as a randomized trial. The pharmacokinetic and pharmacodynamic data are fairly consistent, though the relationship with clinical outcomes is uncertain and controversial. Nevertheless, if all proton pump inhibitor options are easily available and similarly priced, to initiate therapy with a proton pump inhibitor that does not have this potential interaction seems prudent.

\section{Deepak L. Bhatt MD MPH}

Professor, Harvard Medical School, Boston, Mass.

\section{References}

1. Juurlink D. Clopidogrel and proton pump inhibitors [letter]. CMAJ 2014;186:212-13.

2. Matteau A, Bhatt DL. Recent advances in antithrombotic therapy after acute coronary syndrome. CMAJ 2013; Nov. 4 [Epub ahead of print].

CMAJ 2014. DOI:10.1503/cmaj.114-0015

\section{The quality of mercy}

In their $C M A J$ commentary, Cook and colleagues ${ }^{1}$ point out deficiencies in end-of-life care in Canada, in particular that many people receive unwanted life support, and are cared for in institutions when they would prefer to die at home.

Unfortunately, the authors do not mention the obvious corollary to avoidance of unwanted life support, namely ending a life that is becoming more intolerable with each passing day. The lack of such an option in Canada must be a fundamental component of any discussion of end-of-life care.

It may be that skilled nursing and appropriate medication in a modern palliative care setting can alleviate most physical suffering. However, for some people, the chief misery at the end of life may not be from physical suffering, but from the loss of privacy, dignity, purpose and independence.

Even though suicide is a legal act, helping someone end his or her life remains a criminal offence. In spite of polls indicating that a majority of Canadians believe such assistance should be available if requested, the present federal government is clear that it will not change the law; the Canadian Medical Association also seems to prefer the status quo.

In the end, it all comes down to one simple question, "Whose decision should it be?" The answer can be found in another question, "Whose life is it?"

\section{John S. Mackay MD}

Retired pathologist

\section{Reference}

1. Cook D, Rocker G, Heyland D. Enhancing the quality of end-of-life care in Canada. CMAJ 2013; 185:1383-4

CMAJ 2014. DOI:10.1503/cmaj.114-0013

\section{Independent research needed to inform end-of- life policy choices}

In their CMAJ editorial, Flegel and Fletcher ${ }^{1}$ call for a national dialogue on end-of-life care, arguing that policy change should not be the result of a single court decision. ${ }^{1}$ In Canada, different medical end-of-life practices, such as treatment withdrawal, use of medication justified by symptom management and use of lethal drugs are being debated. ${ }^{2-4}$ Concerns about the effects of policies are central to the Canadian debate, and international evidence is quoted by proponents and opponents of legislative reforms.

We recently conducted a scoping review of international evidence on medical end-of-life practices, with a focus on the use of lethal drugs by physicians. ${ }^{5}$ Key findings from this review are currently relevant to public debate. We found no empirical study on the use of lethal drugs by physicians in Canada, which is surprising given frequent claims that "assisted suicide," "euthanasia" or "medical aid in dying" are being practised illegally in Canada.

Policy-makers should therefore be careful in drawing conclusions about what is known, and not known, about the likely effects of policies.

Scientific evidence alone cannot provide simple answers to complex end-of-life care dilemmas. However, having robust knowledge publicly available is a precondition for informed democratic deliberation on end-of-life care in Canada.

Antoine Boivin MD PhD, Isabelle Marcoux PhD, Geneviève Garnon MSc, Evert van Leeuwen PhD, Nicholas Mays, Raynald Pineault PhD, Marie-Claude

Prémont PhD, Pascale Lehoux PhD

Department of family and emergency medicine (Boivin, Garnon), Université de Sherbrooke, Sherbrooke, Que.; Faculty of Health Science (Marcoux), University of Montréal, Montréal, Que.; Scientific Institute for Quality Healthcare (van Leeuwen),

Radboud University, Nijmegen, the

Netherlands; Health Services Research and Policy Department (Mays), London School of Hygiene and Tropical Medicine, London, UK; Institut National de Santé Publique du Québec, department de santé publique de Montréal (Pineault); École nationale d'administration publique (Prémont); Institut de recherché en santé publique de l'Université de Montréal, department of health administration, Université de Montréal (Lehoux), Montréal, Que.

\section{References}

1. Flegel K, Fletcher J. Choosing when and how to die: Are we ready to perform therapeutic homicide? CMAJ 2012;184:1227.

2. Carter v. Canada (Attorney General), 2012 BCSC886. No. S112688.

3. Vogel L. Legal ambiguities surround authority to make end-of-life decisions. CMAJ 2011;183:E617-8.

4. Bill 52: An Act respecting the end-of-life. Quebec (QC): National Assembly of Québec; 2013.

5. Boivin A, Marcoux I, Mays N, et al. What evidence is available about the medical practice of euthanasia in contexts of prohibition and legalization? A scoping review. Proceeding from the North American Primary Care Research Group conference; 2013 Nov. 10-12; Ottawa (ON).

CMAJ 2014. DOI:10.1503/cmaj.114-0012 